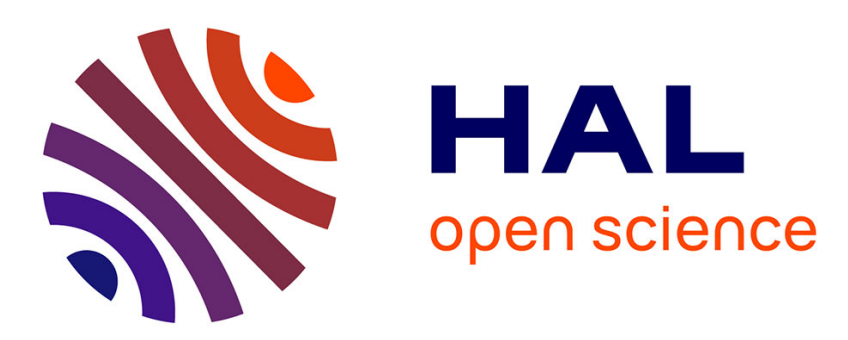

\title{
DEBtox theory and matrix population models as helpful tools in understanding the interaction between toxic cyanobacteria and zooplankton
}

Elise Billoir, Aloysio da Silva Ferrão-Filho, Marie Laure Delignette-Muller, Sandrine Charles

\section{To cite this version:}

Elise Billoir, Aloysio da Silva Ferrão-Filho, Marie Laure Delignette-Muller, Sandrine Charles. DEBtox theory and matrix population models as helpful tools in understanding the interaction between toxic cyanobacteria and zooplankton. Journal of Theoretical Biology, 2009, 258 (3), pp.380. 10.1016/j.jtbi.2008.07.029 . hal-00554502

\section{HAL Id: hal-00554502 \\ https://hal.science/hal-00554502}

Submitted on 11 Jan 2011

HAL is a multi-disciplinary open access archive for the deposit and dissemination of scientific research documents, whether they are published or not. The documents may come from teaching and research institutions in France or abroad, or from public or private research centers.
L'archive ouverte pluridisciplinaire HAL, est destinée au dépôt et à la diffusion de documents scientifiques de niveau recherche, publiés ou non, émanant des établissements d'enseignement et de recherche français ou étrangers, des laboratoires publics ou privés. 


\section{Author's Accepted Manuscript}

DEBtox theory and matrix population models as helpful tools in understanding the interaction between toxic cyanobacteria and zooplankton

Elise Billoir, Aloysio da Silva Ferrão-Filho, Marie Laure Delignette-Muller, Sandrine Charles

PII:

S0022-5193(08)00368-8

DOI: doi:10.1016/j.jtbi.2008.07.029

Reference: $\quad$ YJTBI 5220

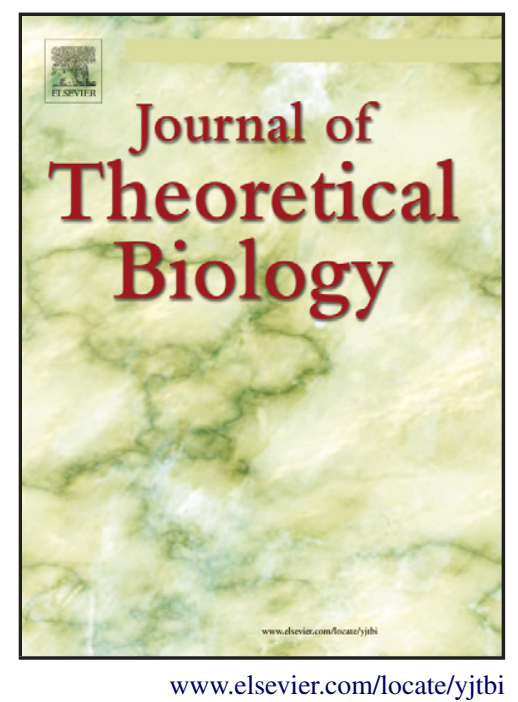

To appear in: $\quad$ Journal of Theoretical Biology

Received date: $\quad 5$ February 2008

Revised date: $\quad 16$ June 2008

Accepted date: 15 July 2008

Cite this article as: Elise Billoir, Aloysio da Silva Ferrão-Filho, Marie Laure DelignetteMuller and Sandrine Charles, DEBtox theory and matrix population models as helpful tools in understanding the interaction between toxic cyanobacteria and zooplankton, Journal of Theoretical Biology (2008), doi:10.1016/j.jtbi.2008.07.029

This is a PDF file of an unedited manuscript that has been accepted for publication. As a service to our customers we are providing this early version of the manuscript. The manuscript will undergo copyediting, typesetting, and review of the resulting galley proof before it is published in its final citable form. Please note that during the production process errors may be discovered which could affect the content, and all legal disclaimers that apply to the journal pertain. 


\title{
DEBtox theory and matrix population models as helpful tools in understanding the interaction between toxic cyanobacteria and zooplankton
}

\author{
Elise Billoir ${ }^{\mathrm{a}, *}$, Aloysio da Silva Ferrão-Filho ${ }^{\mathrm{b}}$, \\ Marie Laure Delignette-Muller ${ }^{c}$, Sandrine Charles ${ }^{\mathrm{a}}$ \\ ${ }^{a}$ Université de Lyon, F-69000, Lyon ; Université Lyon 1; CNRS, UMR5558, \\ Laboratoire de Biométrie et Biologie Evolutive, F-69622, Villeurbanne, France \\ ${ }^{\mathrm{b}}$ Laboratório de Avaliação e Promoção da Saúde Ambiental, FIOCRUZ, Av. \\ Brasil, 4365 - Manguinhos, Rio de Janeiro, Brazil \\ c Université de Lyon, F-69000, Lyon ; Unité de Microbiologie Prévisionnelle et \\ Alimentaire, Ecole Nationale Vétérinaire de Lyon, 1 avenue Bourgelat, 69280 \\ Marcy l'Etoile, France
}

Abstract

Preprint submitted to Elsevier 


\footnotetext{
* Corresponding author. Adress: billoir@biomserv.univ-lyon1.fr
} further refining the analysis of ecotoxicological data.

Key words: allometry, DEBtox models, matrix population model, Bayesian inference, Moina micrura, Microcystis aeruginosa

Bioassays were performed to find out how field samples of the toxic cyanobacteria Microcystis aeruginosa affect Moina micrura, a cladoceran found in the tropical Jacarepagua Lagoon (Rio de Janeiro, Brazil). The DEBtox approach has been proposed for use in analysing chronic toxicity tests as an alternative to calculating the usual safety parameters (NOEC, ECx). DEBtox theory deals with the energy balance between physiological processes (assimilation, maintenance, growth and reproduction), and it can be used to investigate and compare various hypotheses concerning the mechanism of action of a toxicant. Even though the DEBtox framework was designed for standard toxicity bioassays carried out with standard species (fish, daphnids), we applied the growth and reproduction models to M.micrura, by adapting the data available using a weight-length allometric relationship. Our modelling approach appeared to be very relevant at the individual level, and confirmed previous conclusions about the toxic mechanism. In our study we also wanted to assess the toxic effects at the population level, which is a more relevant endpoint in risk assessment. We therefore incorporated both lethal and sublethal toxic effects in a matrix population model used to calculate the finite rate of population change as a continuous function of the exposure concentration. Alongside this calculation, we constructed a confidence band to predict the critical exposure concentration for population health. Finally, we discuss our findings with regard to the prospects for 


\section{Introduction}

One of the main objectives in ecotoxicology is to provide an estimation of safety parameters, e.g. No Observed Effect Concentration (NOEC) and x\% Effect Concentration (ECx), that can be derived from standardarized toxicity tests (OECD, 1998; ISO, 2000). These approaches have been criticized for many reasons: 1) NOEC and ECx usually focus on a single endpoint (mortality, growth or reproduction); 2) the standard tests involve a fixed exposure time, irrespective of the properties of the chemical being tested; 3) they generally use only a few standard species, which may not be relevant to the ecosystem being investigated; 4) NOEC and ECx are based on purely descriptive regression models, and are unrelated to the physiological processes of the organisms that are being tested, and to the toxicokinetics of the compound being tested (Chapman, 1996; Kooijman \& Bedaux, 1996; Péry et al., 2002; Jager et al., 2004, 2006). Biology-based models, such as DEBtox (Dynamic Energy Budget Theory applied to toxicity data) (Kooijman \& Bedaux, 1996), have been proposed to overcome these shortcomings: 1) this modelling approach is based on the concept of No Effect Concentration (NEC), which is common to several biological processes and consequently to several sublethal endpoints (e.g. growth and reproduction); 2) DEBtox models take into account the toxicokinetics of the chemical being tested; 3) they were originally developped for a standard panel of species, but they can be adapted to others; 4) DEBtox theory is a mechanistic modelling approach, based on several assumptions about how the test compound disrupts the energy balance between the various physiological processes.

In addition, ecotoxicology is now attempting to assess the impact of chemical 
compounds not only on individuals, but also at higher organizational levels. For example, the population level is particularly relevant when different life stages may display different susceptibilities to toxic compounds (Emlen \& Springman, 2007). In this case, the finite rate of population increase $\lambda$ is considered to be a robust endpoint (Forbes \& Calow, 1998). Various methods can be used to relate the effects of a compound on individuals to its impact on the finite rate of population increase. The one we chose was the matrix population model approach, which has already been successfully combined with DEBtox models (Lopes et al., 2005; Billoir et al., 2007).

Cyanobacteria are some of the most ancient organisms on Earth ( $\simeq 4$ billion years), and the first to develop the ability to fix atmospheric carbon and release oxygen through photosynthesis. Another distinguishing characteristic of cyanobacteria is the fact that they produce secondary metabolites with toxic properties, known as cyanotoxins (Carmichael, 1992). Cyanotoxins have been responsible worldwide for deaths of wild and domestic animals, and also for some human fatalities (Ressom et al., 1994; Jochimsen et al., 1998; Carmichael et al., 2001). The most common cyanotoxins are the hepatotoxic peptides, which are produced by some genera of freshwater bloom-forming cyanobacteria such as Microcystis, Anabaena and Oscillatoria. In spite of the effects observed in non-target organisms, such as mammals, one of the most generally accepted hypotheses to explain the evolutionary role of these toxins is that they are produced to protect cyanobacteria against their main predators, including the herbivorous zooplankton, such as Daphnia. According to this hypothesis, cyanotoxins act as chemical defenses against zooplankton predators, by decreasing their fitness (Lampert, 1981, 1987). The interaction between cyanobacteria and zooplankton has been widely used as a model system to 
study the evolutionary role of cyanotoxins. Also, since cyanotoxins also pose some risk to human health, the ecotoxicology of the cyanobacteria-zooplankton system is used to study the mechanisms of action of these toxins in aquatic organisms, and can be used as the basis for guidelines for environmental health and water quality as well.

In this study, we used ecotoxicological data from the study of Ferrão-Filho \& Azevedo (2003), which reported the effects of naturally-occurring cyanobacteria from a hypereutrophic coastal lagoon in Brazil, including data from lifetable and growth experiments with Moina micrura Kurs, a tropical freshwater cladoceran. In contrast to the big temperate cladocerans, such as Daphnia (2.0-4.0 mm body size), M. micrura is much smaller (0.8-1.0 mm body size), reaches maturity after only 2-3 days, and has a shorter life-cycle (no more than 20 days).

Our main goal was to study the interaction between Microcystis and M. micrura by applying the DEBtox modelling framework to experimental data, in order to validate some hypotheses, in particular concerning the mechanism of action of the toxicant. Our second goal was to improve the ecotoxicological relevance of the analysis. To do this, both lethal and sublethal effect models were included in matrix population models, allowing us to extrapolate the impact of toxic effects observed in individuals to the population level. Moreover, a confidence band was added to the population endpoint to predict critical exposure concentrations for population health. 


\section{Models and Methods}

\subsection{Data}

The data were obtained from life-table and growth experiments (Experiments 2 and 5, respectively, described in Table I in the study of Ferrão-Filho \& Azevedo (2003)), carried out with a sample of a naturally occurring bloom of cyanobacteria from Jacarepaguá Lagoon, in Rio de Janeiro (Brazil). The sample consisted of particulate material (seston) collected with a plankton net (25 $\mu \mathrm{m})$. This sample was centrifuged, and the supernatant containing large colonies was discarded, while the settled material was used in the experiments. This material consisted mostly of single cells and small colonies of Microcystis (5-20 $\mu \mathrm{m})$, and a small proportion of algae and detritus. Different concentrations of seston, expressed as organic carbon $\left(0.25\right.$ to $\left.1.5 \mathrm{mg} \mathrm{C} \mathrm{L}{ }^{-1}\right)$, were used in the experiments. The microcystin (toxin) concentration in this sample was $3.1 \mathrm{mg} \mathrm{g}^{-1}$ of dry weight, and nominal microcystin concentrations in the seston treatments ranged from 1.6 to $9.4 \mu \mathrm{g} \mathrm{L}^{-1}$. The controls $(0.0 \mathrm{mg} \mathrm{C} \mathrm{L}-1$ of seston) consisted of animals fed solely with nutritious green algae at the concentration of $1.0 \mathrm{mg} \mathrm{C} \mathrm{L}{ }^{-1}$. To avoid interference from nutrition factors, as a result of a poor food supply, the same amount of green algae was mixed with all the seston treatments.

The life-table experiment was performed with 20 replicate animals (females) per treatment, and lasted 16 days. Survivorship and neonates produced per female, as the cumulative number of offspring, were recorded daily. The growth experiment was performed with three replicate bottles containing 50 newborns $(<24 \mathrm{~h})$, and lasted 6 days, with samplings for weighting the animals on days 
2,4 and 6.

\subsection{DEBtox modelling}

At the individual level, we used DEBtox modelling (Kooijman \& Bedaux, 1996) to describe the effects of the contaminant on life history traits measured during the experiments (e.g. growth, reproduction). The DEBtox framework is based on the DEB theory, which assumes that energy is derived from food, and is assimilated to constitute reserves. These reserves are shared between three main processes: maintenance, growth, and reproduction. DEBtox models deal with sublethal effects by assuming that the contaminant affects the energy balance, and consequently affects growth and reproduction. The DEBtox theory also comprises a contamination kinetics model and a survival model for the lethal effects of the toxicant. These different parts are presented below. All DEBtox variables and parameters are summarized in Table 1.

\subsubsection{Toxicological aspects}

Lethal and sublethal effects of a contaminant are modelled using the following stress function:

$$
s\left(c_{q}(t)\right)=c_{*}^{-1}\left(c_{q}(t)-N E C_{*}\right)_{+}
$$

where $\left(c_{q}(t)-N E C_{*}\right)_{+}=\max \left(0, c_{q}(t)-N E C_{*}\right)$. Indeed, in accordance with the DEBtox theory (Kooijman \& Bedaux, 1996), the contaminant is assumed to produce an effect when the concentration inside the organisms $\left(c_{q}(t)\right)$ exceeds a concentration called the No Effect Concentration $\left(N E C_{*}, *=L\right.$ for the lethal effects, $*=S$ for the sublethal effects). Moreover, the toxic effect is 
assumed to be proportional to the excess above the $N E C_{*} \cdot C_{*}$ is the so-called tolerance concentration (Kooijman \& Bedaux, 1996), which can be seen as a kind of toxicity rate reciprocal $(*=L$ for the lethal effects, $*=H, R, A, G$, or $M$ for the sublethal effects, depending on the mechanism of action being considered (see Sublethal effects)). $c_{q}(t)$ corresponds to the scaled concentration of the toxic compound inside the organism at time $t$, determinated by the following one-compartment kinetic model:

$\frac{d c_{q}(t)}{d t}=\frac{c \dot{k}_{e}}{l(t)}-c_{q}(t)\left(\frac{\dot{k}_{e}}{l(t)}+\frac{d \ln \left(l(t)^{3}\right)}{d t}\right)$

where $\dot{k}_{e}$ is the elimination rate, $c$ the exposure concentration and $l(t)$ the scaled body length at time $t$. The initial condition for the contamination kinetics equation was set at $c_{q}(t=0)=0$, as exposure started at the beginning of the experiment. For a more detailed explanation of this kinetics, see Kooijman \& Bedaux (1996).

\subsubsection{Lethal effects}

As far as the lethal effects were concerned, we used a classical modelling with a tolerance function $q(t, c)$ expressed as the exponential of minus a cumulative hazard function. Thus, the probability $q(t, c)$ of surviving until time $t$ with an exposure concentration of $c$ can be written as follows:

${ }_{160} q(t, c)=\exp \left(-\int_{0}^{t} \dot{h}(\tau, c) d \tau\right)$ 
161

163

where $\dot{h}(\tau, c)$ is the hazard rate at time $\tau$ and exposure concentration $c . \dot{h}(\tau, c)$ is written as follows:

$\dot{h}(\tau, c)= \begin{cases}\dot{m}+s\left(c_{q}(\tau)\right) & \text { if } c>N E C_{L} \text { and } \tau>t_{0} \\ \dot{m} & \text { else }\end{cases}$

where $t_{0}$ is the time at which $c_{q}(\tau)$ exceeds $N E C_{L}: t_{0}=-\dot{k}_{e}^{-1} \ln \left(1-\frac{N E C_{L}}{c}\right)$ being defined only if $c>N E C_{L}$.

\subsubsection{Sublethal effects}

Five possible mechanisms of action were proposed to deal with sublethal effects of the contaminant on the various processes considered in the DEBtox framework (assimilation, maintenance, growth, reproduction): an increase in maintenance costs (Maintenance), an increase in growth costs (Growth), a decrease in assimilation (Assimilation), an increase in egg production costs (Costs), or a surmortality during oogenesis (Hazard) (Kooijman \& Bedaux, 1996). These five assumptions led to different equations for modelling growth and reproduction, the endpoints potentially measured in toxicity tests involving zooplankton. Contaminant kinetics, individual growth and reproduction are interrelated, so the corresponding equations had to be considered simultaneously. All the equations are summarized in Table 2 (Billoir et al., in press), and their variables and parameters in Table 1. 


\subsubsection{DEBtox parameter estimation}

In this study, the investment ratio $g$ was fixed at $g=1$, the reference value for control organisms at optimal temperature (Kooijman \& Bedaux, 1996; Kooijman et al., 2003), and the ingestion rate as a fraction of its maximum value, $f$, was fixed at $f=1$, as the organisms were fed ad libitum. We collected data for 16 days, but we only used the data from day 0 to 10 to fit the models, because after 10 days, senescence effects appeared, which were not taken into account in the models. For the estimation of survival DEBtox parameters $\left(\dot{k}_{e}\right.$, $N E C_{L}, \dot{k}_{t}$ and $m$ ), we performed nonlinear regression of equation (3) on the survival data, based on a least squares criterion, implying data independence, homoscedasticity and normal error assumptions. To minimize the residual sum of squares, we used the optim() function implemented in the $\mathrm{R}$ language ( $\mathrm{R}$ Development Core Team, 2007). For the estimation of the growth and reproduction DEBtox parameters $\left(\dot{k}_{e}, N E C_{S}, c_{*}, L_{m}, \gamma, \dot{R}_{m}\right.$ and $\left.l_{p}\right)$, Billoir et al. (in press) have shown that nonlinear regression is sometimes inadequate, so we used Bayesian inference with WinBugs (Lunn et al., 2000) and WBDiff (Lunn, 2004) softwares, as proposed by Billoir et al. (resubmitted). From the arbitrary prior probability distribution for each parameter, Bayesian inference provides estimates as samples of posterior distributions given the data. Moreover, this estimation method made it easy to fit growth and reproduction data simultaneously. In this study, we used slightly informative prior distributions which are summarized in Table 3. After checking the convergence of the estimation process, we considered the posterior distribution means as estimates. $\dot{k}_{e}$ was involved in both the lethal and sublethal models, and consequently it was estimated in two different ways, which could yield different values. Thereafter, though this is questionable (see Discussion), we kept both these estimates, 
and used each for the models for which it had been estimated.

\subsection{Allometric relationship}

As only dry body weight data were available, rather than the body length data required to fit DEBtox models, these two quantities were related using an allometric relationship. The typical form for such a relationship is as follows (Jerison, 1973):

$$
y=a x^{b} \quad \text { or } \quad \log (y)=\log (a)+b \log (x)
$$

where $y$ and $x$ are biological quantities, $a$ and $b$ are both regression parameters. In our case, $y$ corresponded to the body length, and $x$ corresponded to the dry body weight. To estimate the $a$ and $b$ parameters, we performed a linear regression in the log-log representation with data collected between day 2 and 6 in five independent growth experiments performed on M. micrura fed with different kinds of food (data from Ferrão-Filho et al. (2005)). As neither body length nor dry body weight was a controled variable, we used an orthogonal regression method. Once the allometric relationship had been established, we used it to infer body lengths from dry body weights, once again for weight data collected between day 2 and 6 in the toxicity experiments with seston.

\subsection{Matrix population model}

\subsubsection{Principles}

To extrapolate the effects of contaminants from the individual to the population level we used matrix population models, which were first proposed by 
(Leslie, 1945, 1948), and which have already been coupled to DEBtox models (Lopes et al., 2005; Billoir et al., 2007). These discrete time models deal with populations subdivided into classes based on age or body length. Individuals pass from one class to the next at each time step, the number depending on their survival rates. The number of age-class 1 offspring produced by adults depended on their fecundity rates. Only females were taken into consideration in our study. Let $\mathbf{N}(t)$ represent the population at time $t$ (the components of the vector are the size of each class). If $\mathbf{L}$ denotes the Leslie matrix, the population dynamics is modelled using the following matrix equation:

$$
\mathbf{N}(t+1)=\mathbf{L N}(t)
$$

Within this matrix modelling framework, the dominant eigenvalue of $\mathbf{L}$, denoted by $\lambda$, corresponds to the finite rate of population increase (Caswell, 2001; Skalski et al., 2007). If $\lambda>1$, the population increases. The finite rate of population increase, $\lambda$, is related to another common index at the population level, the intrinsic rate of population increase, $r$, with $\lambda=\exp (r)$.

\subsubsection{Application}

In our case, an age-specific population structure was more appropriate, because we had far more information about reproduction and survival as a function of age than about body length, which was deduced from weight measurements using the allometric relationship. The effect models of DEBtox theory provided survival (Equation (3)) and reproduction (Equations (8 to 12)) as functions of time, $t$, and of the toxicant exposure concentration, $c$. This also made it possible to calculate the vital rates as continuous functions of $t$ and $c$.

We decided to use a pre-breeding census (Caswell, 2001), meaning that data 
${ }^{254} \quad P_{i}(c)=\frac{q(i+1, c)}{q(i, c)}$ were collected just before the birth pulse. Let $P_{i}$ be the probability of surviving from one age class to the next and $F_{i}$ be the fecundity rate, i.e. the number of offspring reaching age class 1 per female of age class $i$. Hence, we got:

where $q(i, c)$ is the probability of surviving until age class $i$ for a toxicant exposure concentration $c$ (Equation $(3)$ ), and $R(t, c)$ is the reproduction rate at time $t$ and exposure concentration $c$ (Equations (8 to 12)).

We used a matrix model with 10 age classes and a time step of 1 day (0-1 day, 1-2 days, ..., 9-10 days), because we used data over 10 days to fit individual models. M. micrura can live and reproduce for more than 10 days, so we added a term $G_{10}$ to the diagonal of the matrix, allowing the organisms to loop in the last age class. However, in the experiments under consideration, almost all of the organisms had died after 16 days, including the controls. Consequently, we used $G_{10}=0.5 P_{9}$, ensuring a survival probability of less than $1 \%$ after 16 days. 
Assuming that reproduction can occur from age class 2, the matrix is written as follows:

$$
\mathbf{L}=\left(\begin{array}{cccccc}
0 & F_{2} & F_{3} & \cdots & F_{9} & F_{10} \\
P_{1} & 0 & 0 & \cdots & 0 & 0 \\
0 & P_{2} & 0 & \cdots & 0 & 0 \\
0 & 0 & P_{3} & \cdots & 0 & 0 \\
\cdots & \cdots & \cdots & \cdots & \cdots & \cdots \\
0 & 0 & 0 & \cdots & P_{9} & G_{10}
\end{array}\right)
$$

where all the matrix coefficients depend on the exposure concentration. To evaluate the effects of cyanobacteria on zooplankton at the population level, the finite rate of population increase, $\lambda$, was plotted as a function of the exposure concentration.

\subsubsection{Confidence interval for $\lambda$}

In order to evaluate a confidence interval for the finite rate of population increase, $\lambda$, we proposed a method based on bootstrapping. For both lethal and sublethal parameters, we drew 10000 DEBtox parameter sets: in their 95 $\%$ Beale joint confidence region (Beale, 1960) for the lethal ones $\left(\dot{k}_{e}, N E C_{L}, \dot{k}_{t}\right.$ and $m$ ) which were estimated by nonlinear regression, and in the sample of the joint posterior distribution for the sublethal ones $\left(\dot{k}_{e}, N E C_{S}, c_{*}, L_{m}, \gamma, \dot{R}_{m}\right.$ and $l_{p}$ ) which was provided by the Bayesian inference. From each parameter set, we next deduced the vital rates of the matrix population model and the 
corresponding $\lambda$, thus we obtained $10000 \lambda$ values. Finally, we considered the $2.5^{\text {th }}$ and $97.5^{\text {th }}$ quantiles of this sample as the limits of a $95 \%$ confidence interval for $\lambda$, the finite rate of population increase.

\section{Results}

\subsection{Allometric relationship}

All the data we used to calculate the allometric relationship are plotted in Figure 1 (A). They were consistent with underlying hypotheses of the model, we did not identify any outlier or marginal value. The orthogonal linear regression gave good results, with distances to the regression line close to normality (Figure $1(\mathrm{~B})$ ). We obtained the following allometric relationship (Jerison, 1973):

$$
y=\exp (6.42) x^{0.144} \quad \text { or } \quad \log (y)=6.42+0.144 \log (x)
$$

$x$ being the dry weight and $y$ being the body length.

\subsection{Lethal effects}

The survival data were fitted by a nonlinear regression based on the least squares criterion. Results are presented in Figure 2. Although the theoretical curves did not all fit the data perfectly (Figure 2), we considered that the fits were satisfactory for our purposes. We were not attempting to describe the survival data accurately, but just wanted to exrapolate the results from the individual level to the population level. 


\subsection{Sublethal effects}

Simultaneous fitting performed by Bayesian inference on growth and reproduction data with the five assumptions about the mechanism of action of the toxicant are shown in Figure 3. For reasons of clarity, data replicates are not shown, and we only plotted the replicate mean for each time and each exposure concentration. Figure 3 allowed us to visualize the quality of fit, and to compare the different assumptions about the seston mechanism of action. The two best models seemed to be the Assimilation and the Maintenance models (Figure $3(\mathrm{~A})$ and $(\mathrm{C})$ ). With these two assumptions of either decreased assimilation or increased maintenance costs, the DEBtox models fitted both the reproduction and growth data well, except for reproduction at $1.0 \mathrm{mg} \mathrm{C} \mathrm{L}{ }^{-1}$. However, we had only few replicates of the data at this concentration, because of high mortality. Consequently, the reproduction data at $1.0 \mathrm{mg} \mathrm{C} \mathrm{L}{ }^{-1}$ were not as reliable as the data measured at lower exposure concentrations.

As far as the other assumptions about mechanism of action of the seston were concerned (Figure 3 (B), (D) and (E)), they clearly disagreed with the growth data. The Costs and Hazard models considered no effect of the contaminant on the growth process (Figure 3 (D2) and (E2)), whatever the exposure concentration. The assumption of increased growth costs (Growth model) (Figure 3 (B2)) did not match the body length data. Moreover, this mechanism of action is marked by a delay in the onset of reproduction as soon as the No Effect Concentration $(N E C)$ is exceeded. This feature is not obvious from the reproduction data (Figure 3 (B1)), as a delay in the onset of reproduction was only noticed for the two highest concentrations of seston (1.0 and $1.5 \mathrm{mg}$ $\mathrm{C} \mathrm{L}^{-1}$, which were less reliable), and although a clear effect of seston was 
already observed at lower concentrations $\left(0.25\right.$ and $\left.0.5 \mathrm{mg} \mathrm{C} \mathrm{L} \mathrm{L}^{-1}\right)$, this was not accompanied by any delay in the onset of reproduction.

\subsection{Population level}

As a population endpoint, the finite rate of population increase $\lambda$ is represented as a function of seston exposure concentration in Figure 4 (A), with the five possible assumptions concerning the toxicological mechanism of action. We have also included in the graph the results reported by Ferrão-Filho \& Azevedo (2003): in their study, they calculated the intrinsic population rate of increase $r$, and we were able to compare this to our results by using $\lambda=\exp (r)$. For exposure concentrations between 0 and $0.5 \mathrm{mg} \mathrm{C} \mathrm{L}^{-1}$, our results seemed to be consistent with those obtained by Ferrão-Filho \& Azevedo (2003), though we obtained slightly lower values in general. From about 0.7 mg C L ${ }^{-1}$, with the Maintenance, Growth and Assimilation models, we observed a drastic drop in population growth due to effects on reproduction. Indeed, using these three assumptions to explain the mechanism of action of the seston, the DEBtox models predicted no reproduction at all for exposure concentrations from $1.0 \mathrm{mg} \mathrm{C} \mathrm{L}^{-1}$ (Figure 3 (A1, B1 and C1)). Consequently, the choice of the mechanism of action strongly influenced the threshold concentration from which the population was predicted to go extinct $(\lambda=1)$, as this threshold concentration ranged from 0.75 to $1.2 \mathrm{mg} \mathrm{C} \mathrm{L}^{-1}$, depending on the mechanism of action considered. Ferrão-Filho \& Azevedo (2003) obtained $\lambda \approx 1.05$ for the exposure concentration of $1.0 \mathrm{mg} \mathrm{C} \mathrm{L}{ }^{-1}$ This prediction was much more optimistic than our results $(\lambda \approx 0.25)$ using the two best models of sublethal effects at the individual level (the Assimilation and Maintenance 
models).

We also calculated a confidence interval for $\lambda$, and in Figure 4 (B) we show the results obtained with the Assimilation model which appeared to be one of the two best models for describing sublethal effects. Calculating a confidence interval for $\lambda$ as a continuous function of exposure concentration led to a confidence band that could also be read horizontally. This enabled us to deduce a prediction interval for the threshold concentration leading to population extinction $(\lambda=1)$ : $0.68-0.82 \mathrm{mg} \mathrm{C} \mathrm{\textrm {L } ^ { - 1 }}$ with the Assimilation model. We obtained similar results with the Maintenance model.

\section{Discussion}

The best fits for our data were obtained with the Assimilation and Maintenance models, which suggests that these indirect effects (a decrease in food assimilation and an increase in maintenance costs) are the most probable mechanisms of action of cyanobacteria on M. micrura. This was consistent with the results of Ferrão-Filho \& Azevedo (2003), which showed that seston containing toxic Microcystis reduced the filtering rate (and therefore the food assimilation) and fitness (measured as the intrinsic rate of population increase, $r$ ) in this cladoceran species. Moreover, microcystins are known to inhibit the activity of protein phosphatase 1 and 2A in Daphnia (DeMott \& Dhawale, 1995), which leads ultimately to the disruption of the cell cytoskeleton (Carmichael, 1992). Recent research has also shown that microcystins can cause gut damage in Daphnia by disrupting contact between gut cells (Rohrlack et al., 2005). This biochemical-cellular mechanism of action of the microcystins is therefore completely compatible with the decrease in assimi- 
lation predicted by DEBtox models used to analyse the data of M. micrura exposed to toxic Microcystis containing microcystins.

An important assumption of DEB theory is that food is shared between four main metabolic processes: assimilation, somatic maintenance, growth and reproduction. As cyanobacteria form part of the zooplankton diet, they are also a source of energy, and so toxins (i.e. microcystins) can be assimilated directly with food from the gut. Our findings show that the DEBtox theory can provide an excellent framework for studying the effects of cyanobacteria on zooplankton, since the exposure of zooplankton to cyanotoxins is directly coupled to the assimilation of food in the gut, and can therefore interfere with the energy balance.

As far as DEBtox parameter estimation was concerned, we used a set of methods that had already been proposed: nonlinear regression for survival models (Kooijman \& Bedaux, 1996; Billoir et al., 2007), and Bayesian inference for the growth and reproduction models (Billoir et al., resubmitted). However, when growth, reproduction and survival data are all available, it would be more logical to estimate all the parameters simultaneously especially because the kinetic parameter $\dot{k}_{e}$ is involved in both the sublethal and lethal models. Jager et al. (2004) performed a simultaneous estimation of this type, but they ran into some statistical issues, such as very large confidence intervals, and the need to fix $\dot{k}_{e}$. We are currently trying to extend the Bayesian approach by integrating a survival module into the Bayesian model. We hope to report the results of this work in the near future.

At the population level, our results and those of Ferrão-Filho \& Azevedo (2003) differ somewhat. Using the data collected for the exposure concentration of 
$1.0 \mathrm{mg} \mathrm{C} \mathrm{L}{ }^{-1}$, they obtained an intrinsic rate of population increase $r=0.042$ (equivalent to $\lambda=\exp (r)=1.043$ ). In contrast, our results for the Assimilation and Maintenance models were much more pessimistic $(\lambda \ll 1)$, indicating that population health was threatened using the same exposure concentration. However, we obtained fewer data for this exposure concentration than for the lower concentrations, as a result of high mortality. Using data collected solely at one exposure concentration did not seem to be as reliable as that obtained by our methodology. Indeed, with the DEBtox modelling approach, all the exposure concentrations tested were considered simultaneously, as the models were continuous in exposure concentration. Moreover, the Bayesian inference took into account the amount of data available for each exposure concentration tested. Combining both approaches made it possible to achieve the best inference of the finite rate of population increase, $\lambda$, as a continuous function of the exposure concentration.

The use of native species, such as M. micrura, and naturally occurring samples of cyanoabacteria are important issues in ecotoxicology, as this leads to better extrapolation of results from laboratory to the field. Although this is not a standard test species, like D. magna, the biology of M. micrura is relatively well known, and has been shown to be very sensitive to cyanobacteria, especially to toxic Microcystis (Ferrão-Filho et al., 2000; Nandini, 2000). However, although the application of DEBtox and matrix population models to natural samples gave more realistic results than when we used laboratory samples (i.e. cultures), caution was still called for when extrapolating from these results to field situations. The threshold concentrations calculated from laboratory toxicity tests could sometimes be underproctective, because other stresses (predation, density-dependence, etc...) were not taken into account. 
In contrast, our results seemed to be overprotective. The predicted threshold concentration range of $0.68-0.82 \mathrm{mg} \mathrm{C} \mathrm{L}^{-1}$, above which the population would become extinct was much lower than the values commonly found in the Jacarepaguá Lagoon (2.7-38.1 mg C L ${ }^{-1}$; (Ferrão-Filho et al., 2002)). Also, in spite of some reported outbreaks of M. micrura populations in this lagoon, it is important to note that this species coexists with high concentrations of Microcystis and microcystins (Ferrão-Filho et al., 2002). This was attributed mainly to the predominance of Microcystis colonies of large size (>20 $\mu \mathrm{m})$ that cannot be eaten by most cladocerans (Ferrão-Filho \& Azevedo, 2003).

Even though the DEBtox framework has been applied to standard toxicicity bioassays involving D. magna, a much larger cladoceran, our results showed that this model can also be applied to other zooplankton species, such as $M$. micrura, which is a much smaller cladoceran with a shorter life cycle. Once again, the combination of DEBtox and matrix population models appeared very useful when extrapolating from the individual to the population level. All lethal and sublethal effects were integrated into the finite rate of population increase, which is much more ecologically relevant than any statistically-based parameter (such as NOEC and ECx) derived from a single endpoint (such as mortality, growth or reproduction). Moreover, our methodology made it possible to calculate the finite rate of population increase as a continuous function of time. Thanks to matrix population modelling, sensitivity analysis could also be used to gain demographic information, as in Billoir et al. (2007). Here, we used a fresh approach: parameter uncertainty was taken into account and integrated into a confidence band, which enabled us to provide a prediction interval for the threshold concentration leading to population extinction (when $\lambda$ becomes $<1)$. In conclusion, our results showed the potential value of us- 
ing nested models to predict the threshold concentrations of cyanobacteria required for zooplankton population extinction to occur. These could be used as parameters in guidelines for protecting both aquatic life and environmental health.

\section{Acknowledgements}

This work was supported by the Cluster Environnement Rhône-Alpes, and the associated team ArcoIris.

\section{References}

BEALE, E. (1960). Confidence regions in nonlinear estimation (with discussion). Journal of the Royal Statistical Society, Ser B. 22, 41-88.

Billoir, E., PÉry, A. \& Charles, S. (2007). Integrating the lethal and sublethal effects of toxic compounds into the population dynamics of Daphnia magna: a combination of the DEBtox and matrix population models. Ecological Modelling 203(3-4), 204-214.

Billoir, E., Delignette-Muller, M.-L., PÉry, A. Geffard, O. \& Charles, S. (in press). Statistical cautions when estimating DEBtox parameters. Journal of Theoretical Biology. http://dx.doi.org/10.1016/j.jtbi.2008.05.006

Billoir, E., Delignette-Muller, M.-L., Péry, A. \& Charles, S. (resubmitted). A Bayesian approach to estimate DEBtox parameters. Resubmitted to Environmental Science and Technology. 
Carmichael, W. (1992). Cyanobacteria secondary metabolites: the cyanotoxins. Applied Bacteriology 72, 445-454.

Carmichael, W., Azevedo, S., Na, J., Molica, R., Jochimsen, E., Lau, S., Rinehart, K., Shaw, G. \& Eaglesham, G. (2001). Human fatalities from cyanobacteria: chemical and biological evidences for cyanotoxins. Environ. Health Perspect. 109, 663-668.

Caswell, H. (2001). Matrix Population Models - Construction, analysis, and interpretation. Sunderlands, Massachussets: Sinauer Associates, 2nd ed.

Chapman, P. (1996). A warning: NOECs are inappropriate for regulatory use. Environ. Toxicol. Chem. 15, 77-79.

DeMott, W. \& Dhawale, S. (1995). Inibition of in vitro protein phosphatase activity in three zooplankton species by microcystin-LR, a toxin from cyanobacteria. Archiv für Hydrobiologie 134, 417-424.

EmLen , J. \& Springman, K. (2007). Developing methods to assess and predict the population level effects of environmental contaminants. Integrated Environmental Assessment and Management 2, 157-165.

Ferrão-Filho, A. \& AzEvedo, S. (2003). Effects of unicellular and colonial forms of Microcystis aeruginosa from laboratory cultures and natural populations on two tropical cladocerans. Aquatic ecology 37, 23-35.

Ferrão-Filho, A., DeMott, W. \& Azevedo, S. (2000). Effects of toxic and non-toxic cyanobacteria in the life-history of tropical and temperate cladocerans. Freshwater biology 45, 1-19.

Ferrão-Filho, A., Domingos, P. \& Azevedo, S. (2002). Influences of a Microcystis aeruginosa Kützing bloom on zooplankton populations in Jacarepaguá Lagoon (Rio de janeiro, Brazil). Limnologica 32, 295-308.

Ferrão-Filho, A., Arcifa, M. \& Fileto, C. (2005). Influence of seston quantity and quality on growth of tropical cladocerans. Brazilian Journal 
of Biology 65(1), 767-770.

Forbes, V. \& Calow, P. (1998). Is the per capita rate of increase a good measure of population-level effects in ecotoxicology? Environmental Toxicology and Chemistry 18 (7), 1544-1556.

ISO.(2000) ISO 10706:2000 Water quality - Determination of long term toxicity of substances to Daphnia magna Straus (Cladocera, Crustacea). International Organization for Standardization.

Jager, T., Crommentuijn, T., van Gestel, C. \& Kooijman, S. (2004). Simultaneous modeling of multiple endpoints in life-cycle toxicity tests. Environmental Science and Technology 38, 2894-2900.

Jager, T., Heugens, E. \& Kooijman, S. (2006). Making sense of ecotoxicological test results: towards application of process-based models. Ecotoxicology 15, 305-314.

JERISON, H. (1973). Evolution of the brain and intelligence. New York : Academic Press.

Jochimsen, E., Carmichael, W., An, J., Cardo, D., Cookson, S., Holmes, C., Antunes, B., Filho, D., Lyra, T., Barreto, V., Azevedo, S. \& JARvis, W. (1998). Liver failure and death after exposure to microcystins at a hemodialysis center in Brazil. New England Journal of Medicine 338, 873-878.

Kooljman, S. \& Bedaux, J. (1996). The analysis of aquatic toxicity data. Amsterdam: VU University Press.

Kooljman, S., Bedaux, J., Péry, A. \& Jager, T. (2003). Water quality - Guidance document on the statistical analysis of ecotoxicity data, chap. 7. H. Magaud.

LAMPERT, W. (1981). Toxicity of blue-green Microcystis aeruginosa: effective defense mechanism againt grazing pressure by Daphnia. Verhanlungen 
der internationalen Vereinigung für theoretische und angewandte Limnologie 21, 1436-1440.

LAMPERT, W. (1987). Laboratory studies on zooplankton-cyanobacteria interactions. N. Zeland J. Mar. and Fres. Res 21, 483-490.

Leslie, P. (1945). On the use of matrices in certain population mathematics. Biometrika 33(3), 184-212.

Leslie, P. (1948). Some further notes on the use of matrices in population mathematics. Biometrika 35(3-4), 213-245.

Lopes, C., Péry, A., Chaumot, A. \& Charles, S. (2005). Ecotoxicology and population dynamics: on the use of DEBtox models in a Leslie modelling approach. Ecological Modelling 188, 30-40.

Lunn, D., Thomas, A., Best, N. \& Spiegelhalter, D. (2000). Winbugs - a bayesian modelling framework: Concepts, structure, and extensibility. Statistics and Computing 10, 325-337.

Lunn, D. (2004). WinBUGS Differential Interface - Worked examples. Imperial School of Medicine, London, UK, 2004.

NAndini, S. (2000). Responses of rotifers and cladocerans to Microcystis aeruginosa (Cyanophyceae): a demographic study. Aquatic ecology 34, 227242.

OECD (1998). OECD guidelines for testing of chemicals. Daphnia magna reproduction test. Organisation for Economic Co-operation and Development. Péry, A., Flammarion, P., Vollat, B., Bedaux, J., Kooijman, S. \& Garric, J. (2002). Using a biology-based model (DEBtox) to analyze bioassays in ecotoxicology: opportunities and recommendations. Environmental Toxicology and Chemistry 21(2), 459-465.

R Development Core Team (2007). R: A Language and Environment for Statistical Computing. R Foundation for Statistical Computing, Vienna, 
Austria. ISBN 3-900051-07-0.

Ressom, R., Soong, F., Fitzgerald, J., Turczynowicz, L., SaAdi, O. E., Roder, D., Maynard, T. \& Falconer, I. (1994). Health effects of toxic cyanobacteria (blue-green algae) Canberra, Australia. Australian Government Public Service.

Rohrlack, T., Christoffersen, K., Dittmann, E., Nogueira, I., VAsconcelos, V. \& Börner, T. (2005). Ingestion of microcystins by Daphnia: intestinal uptake and toxic effects. Limnology and Oceanography 50, 440-448.

Skalski, J., Millspaugh, J., Dillingham, P. \& Buchanan, R. (2007). Calculating the variance of the finite rate of population change from a matrix model in Mathematica. Environmental Modelling and Software 22, 359-364.

Spiegelhalter, D., Thomas, A., Best, N. \& Lunn, D. (2007). WinBUGS Version 1.4 User Manual. MRC Biostatistics Unit, Cambridge, UK, 2003. 


\begin{tabular}{|c|c|c|c|}
\hline Symbol & Status & Dimension & Interpretation \\
\hline$t$ & covariable & $\mathrm{T}$ & time from the experiment beginning, and also organism age \\
\hline$c$ & covariable & $\mathrm{C}$ & exposure concentration \\
\hline$c_{q}$ & variable & $\mathrm{C}$ & internal concentration \\
\hline$s$ & variable & - & stress function \\
\hline$q$ & variable & - & survival probability \\
\hline$\dot{h}$ & variable & $\mathrm{T}^{-1}$ & hazard rate \\
\hline$l$ & variable & - & scaled body length \\
\hline$\dot{R}$ & variable & $\# \mathrm{~T}^{-1}$ & reproduction rate \\
\hline$N E C_{*}$ & parameter & $\mathrm{C}$ & No Effect Concentration for lethal $(*=L)$, sublethal effects $(*=S)$ \\
\hline$c_{*}$ & parameter & $\mathrm{CT}^{-1}$ or $\mathrm{C}$ & tolerance concentration, $*=L, H, R, A, G$, or $M$ \\
\hline$\dot{k}_{e}$ & parameter & $\mathrm{T}^{-1}$ & elimination rate \\
\hline$\dot{m}$ & parameter & $\mathrm{T}^{-1}$ & control mortality rate \\
\hline$l_{b}$ & parameter & - & scaled body length at birth \\
\hline$\dot{\gamma}$ & parameter & $\mathrm{T}^{-1}$ & von Bertalanffy growth rate \\
\hline$l_{p}$ & parameter & & scaled body length at puberty \\
\hline$\dot{R}_{M}$ & parameter & $\# \mathrm{~T}^{-1}$ & maximum reproduction rate \\
\hline$f$ & parameter & - & ingestion rate as a fraction of its maximum \\
\hline$g$ & parameter & - & investment ratio \\
\hline
\end{tabular}

Table 1

Quantities considered in the DEBtox framework, their status (variable, covariable, or parameter), their dimension and their biological interpretation. T, C and \# denote the dimensions of time, concentration and number respectively. Dots denote rates. 


\begin{tabular}{|c|c|c|}
\hline Mode of action & Growth & Reproduction \\
\hline Growth & $\frac{d l}{d t}=\dot{\gamma} \frac{f+g}{f+g\left(1+s\left(c_{q}(t)\right)\right.}(f-l(t)) \quad(4)$ & $\dot{R}(l(t))=\frac{\dot{R}_{M}}{1-l_{p}^{3}}\left[f l(t)^{2}\left(\frac{g\left(1+s\left(c_{q}(t)\right)\right)+l}{g\left(1+s\left(c_{q}(t)\right)\right)+f}\right)-l_{p}^{3}\right] \quad(8)$ \\
\hline Maintenance & $\frac{d l}{d t}=\dot{\gamma}\left(f-l\left(1+s\left(c_{q}(t)\right)\right)\right)(5)$ & $\dot{R}(l(t))=\frac{\dot{R}_{M}}{1-l_{p}^{3}}\left(1+s\left(c_{q}(t)\right)\right)\left[f l(t)^{2}\left(\frac{g\left(1+s\left(c_{q}(t)\right)\right)}{g+f}+l(t)\right.\right.$ \\
\hline Assimilation & $\frac{d l}{d t}=\dot{\gamma} \frac{f+g}{f\left(1-s\left(c_{q}(t)\right)\right)+g}\left(f\left(1-s\left(c_{q}(t)\right)\right)-l(t)\right) \quad(6)$ & $\dot{R}(l(t))=\frac{\dot{R}_{M}^{3}}{1-l_{p}^{3}}\left[f\left(1-s\left(c_{q}(t)\right)\right) l(t)^{2}\left(\frac{g+l(t)}{g+f\left(1-s\left(c_{q}(t)\right)\right)}\right)-l_{p}^{3}\right] \quad(10)$ \\
\hline Hazard & $\frac{d l}{d t}=\dot{\gamma}(f-l(t)) \quad(7)$ & $\dot{R}(l(t))=\frac{\dot{R}_{M}}{1-l_{p}^{3}}\left[f l(t)^{2}\left(\frac{g+l(t)}{g+f}\right)-l_{p}^{3}\right] e^{-s\left(c_{q}(t)\right)} \quad(11)$ \\
\hline Costs & $\frac{d l}{d t}=\dot{\gamma}(f-l(t)) \quad(7)$ & $\dot{R}(l(t))=\frac{\dot{R}_{M}}{1-l_{p}^{3}}\left[f l(t)^{2}\left(\frac{g+l(t)}{g+f}\right)-l_{p}^{3}\right]\left(1+s\left(c_{q}(t)\right)\right)-1 \quad(12)$ \\
\hline
\end{tabular}

Table 2

DEBtox growth and reproduction equations for each assumption about the toxicant mode of action.

\section{Table 3}

\begin{tabular}{|c|c|}
\hline Parameter (unit) & Distribution \\
\hline$L_{m}(\mu \mathrm{m})$ & $N(1000,100) I(500,+\infty)$ \\
\hline$\dot{\gamma}(-)$ & $U(0,2)$ \\
\hline$l_{p}(-)$ & $N(0.75,0.1) I(0.5,1)$ \\
\hline$\dot{R}_{m}\left(\# \mathrm{~d}^{-1}\right)$ & $N(5,2) I(0,+\infty)$ \\
\hline$\dot{k}_{e}\left(\mathrm{~d}^{-1}\right)$ & $U(0.0001,10)$ \\
\hline$N E C\left(\mathrm{mg} \mathrm{C} \mathrm{L}^{-1}\right)$ & $U(0,1.5)$ \\
\hline$c_{*} * H, R, G$, or $M(\mathrm{mg} \mathrm{C} \mathrm{L}-1)$ & $U(0,20)$ \\
\hline$c_{A}\left(\mathrm{mg} \mathrm{C} \mathrm{L}^{-1}\right)$ & $U(2,20)$ \\
\hline
\end{tabular}

Prior distributions used for the DEBtox sublethal parameter estimation which was performed by Bayesian inference. $N(m, s d) I(a, b)$ denotes a normal distribution with mean $m$ and standard deviation $s d$, where $I(a, b)$ represents interval censoring (see Spiegelhalter et al., 2003, p. 12 for details) (Spiegelhalter et al., 2003). $U(c, d)$ denotes a uniform distribution between $c$ and $d$. 
(A)

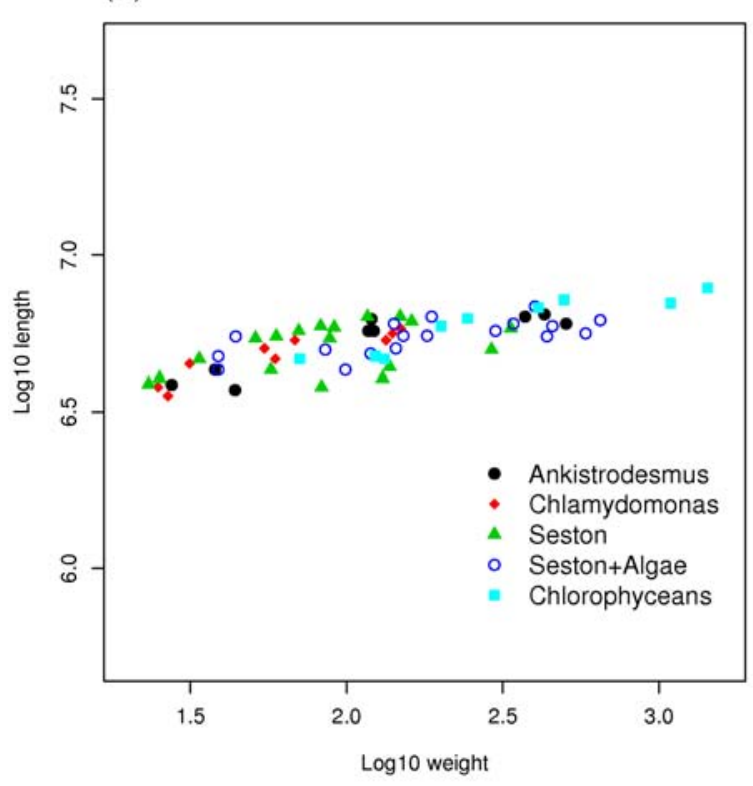

(B) Weights and lengths ( $\mathrm{Log}-\mathrm{Log})$

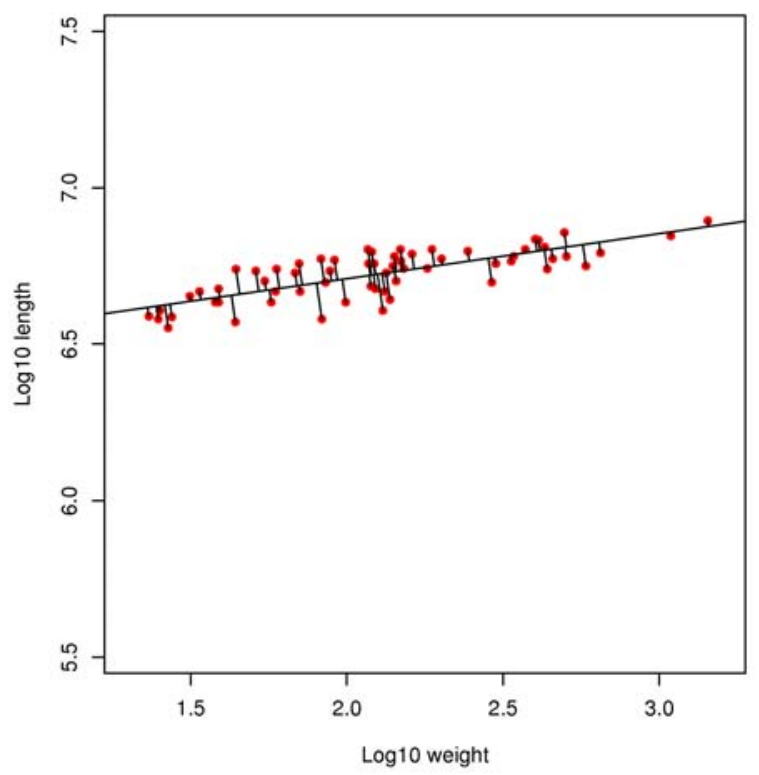

Fig. 1. (A) Log-Log representation of the data used to establish the length/dry weight allometric relationship. Data were collected during experiments involving various kinds of food (data from Ferrão-Filho et al. (2005)). (B) Orthogonal linear regression fit on these data. 


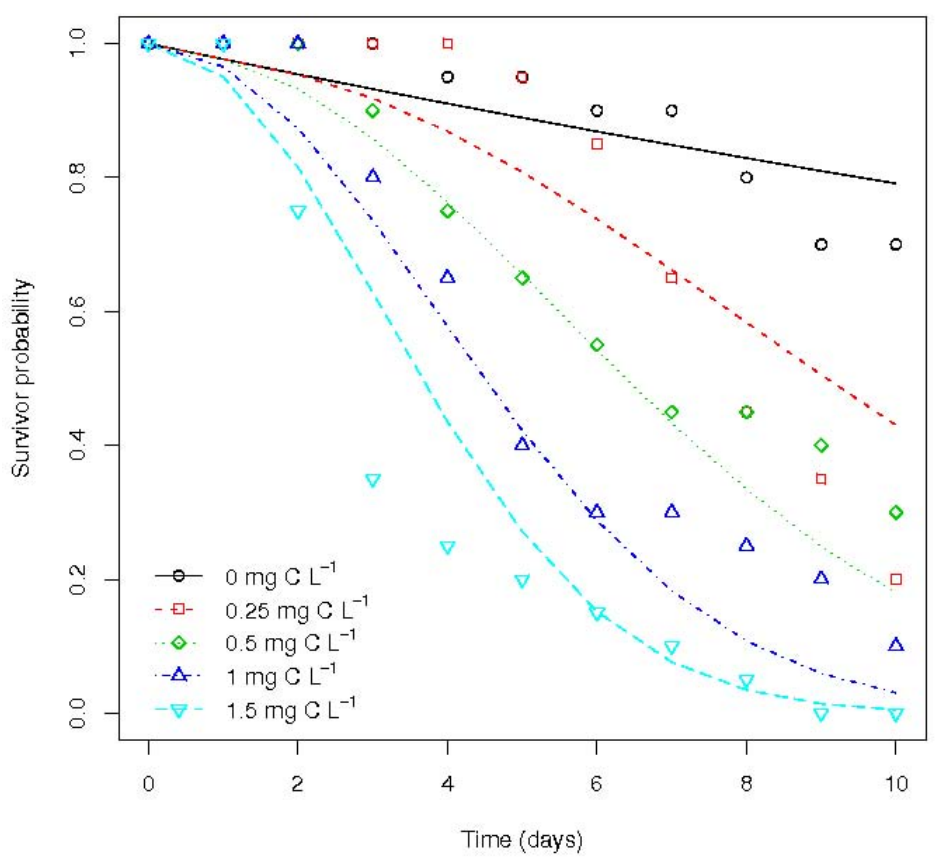

Fig. 2. Fitting performed by nonlinear regression of survival data: time profile of survival probability for various seston exposure concentrations $(0,0.25,0.5,1.0,1.5$ $\operatorname{mg} \mathrm{C} \mathrm{L}^{-1}$ ) 

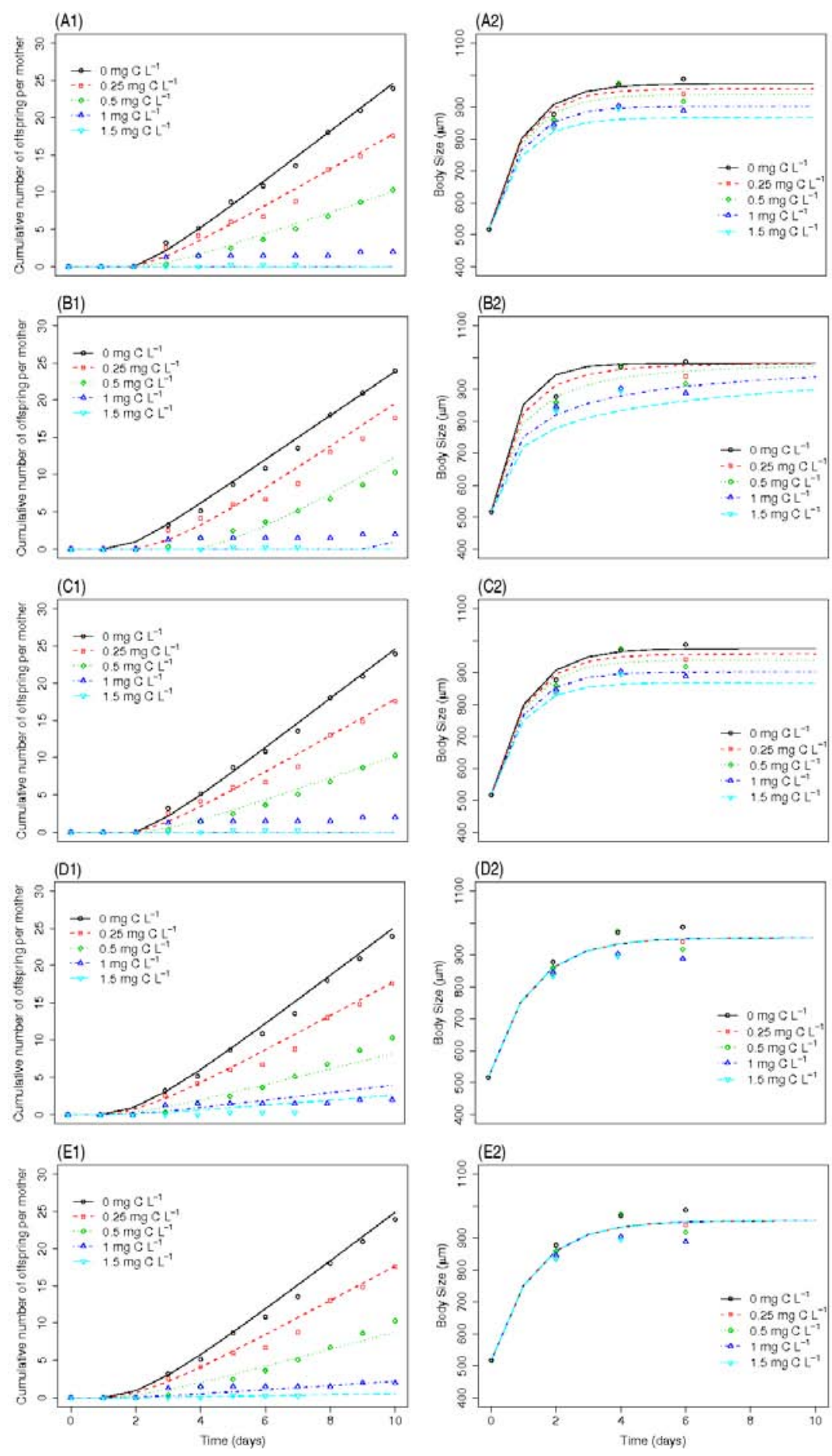

Fig. 3. Simultaneous fitting performed by Bayesian inference of (1) reproduction and (2) growth data under the assumption of (A) a decrease in Assimilation (B) an increase in the Growth costs (C) an increase in the Maintenance costs (D) an increase in egg production Costs, and (E) excess mortality during oogenesis (Hazard): time profiles of the cumulative number of offspring and body length for various seston exposure concentrations $\left(0,0.25,0.5,1.0,1.5 \mathrm{mg} \mathrm{C} \mathrm{L}^{-1}\right)$ 

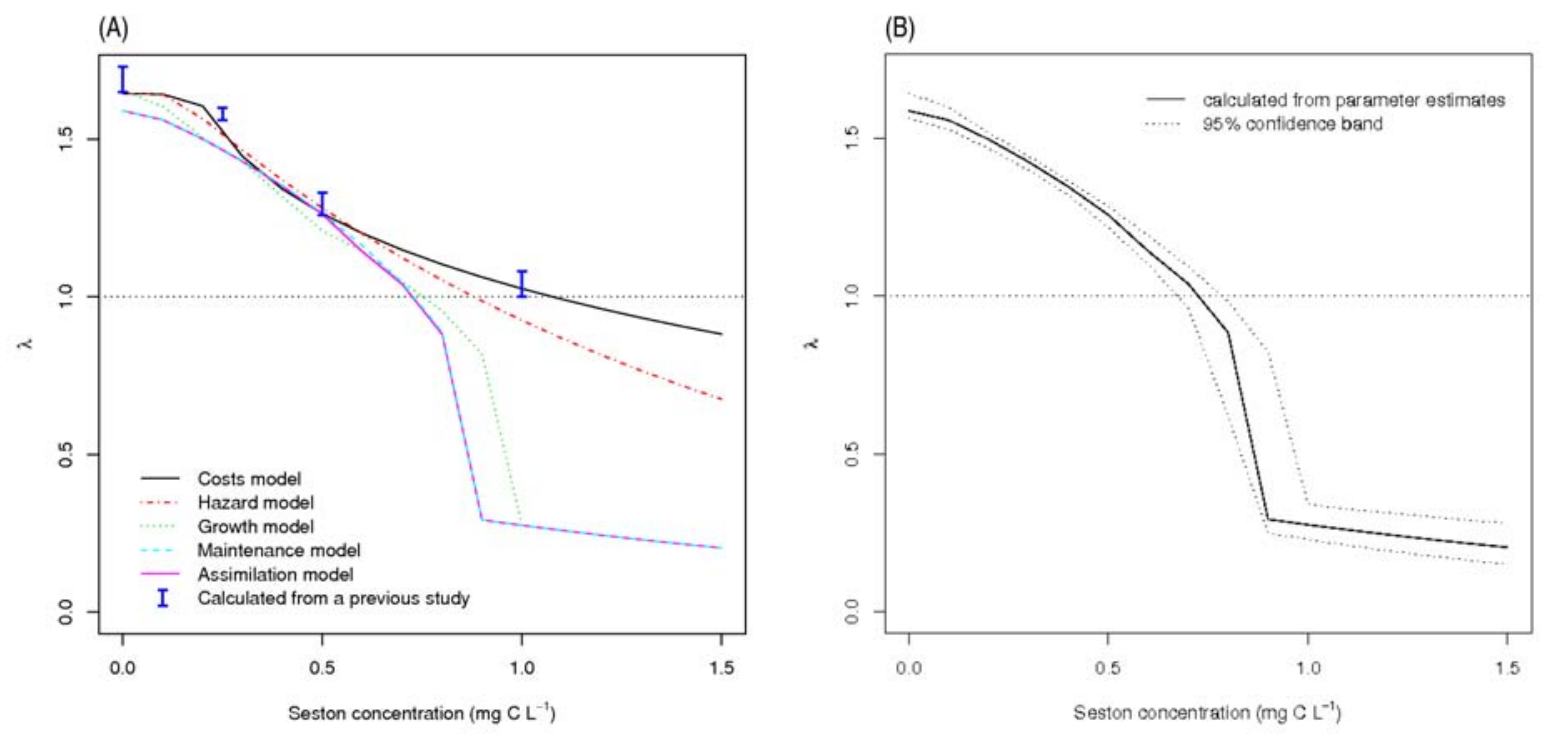

Fig. 4. (A) Evolution of the finite rate of population increase $\lambda$ of $M$. micrura as a function of the seston exposure concentration $\left(\mathrm{mg} \mathrm{C} \mathrm{L} \mathrm{L}^{-1}\right)$. Comparison of the five assumptions about the toxicological mechanism of action: Hazard, Costs, Maintenance, Growth and Assimilation. The results from Ferrão-Filho \& Azevedo (2003) (means \pm SE) are also shown on this graph. (B) Change in the finite rate of population increase $\lambda$ of $M$. micrura and its confidence interval as a function of seston exposure concentration $\left(\mathrm{mg} \mathrm{C} \mathrm{L}^{-1}\right)$ when we assumed that a decrease in Assimilation was the toxicological mechanism of action. 